J. Lake Sci. (湖泊科学), 2013, 25(5): 643-648

http: //www. jlakes. org. E-mail : jlakes@niglas.ac.cn

(C) 2013 by Journal of Lake Sciences

\title{
丰水期鄱阳湖水体中氮、磷含量分布特征"
}

\author{
陈晓玲 ${ }^{1}$, 张 媛 ${ }^{1,3}$, 张 琍 ${ }^{1,2}$, 陈莉琼 ${ }^{1 * *}$, 陆建忠 ${ }^{1}$ \\ (1:武汉大学测绘遥感信息工程国家重点实验室,武汉 430079) \\ $(2$ : 江西师范大学鄱阳湖湿地与流域研究教育部重点实验室, 南昌 330022) \\ $(3:$ 湖北省环境监测中心站, 武汉 430072)
}

摘 要: 以 2011 年 7 月份鄱阳湖实测数据为参考,对鄱阳湖丰水期总氮 ( TN)、总磷 ( TP) 空间分布特征及其影响因素进 行了分析,并就鄱阳湖氮、磷营养盐结构特征及其与叶绿素 $\mathrm{a}$ 的相关性进行了探讨. 结果表明:鄱阳湖氮、磷含量已经达到 了发生富营养化的条件,且 TN 含量呈现由东向西、由南向北逐渐降低的趋势; TP 在几个主要的采砂区,尤其是南北湖交 界处污染最严重. 鄱阳湖以磷限制为主,氮污染相对比较严重, 且氮、磷不是鄱阳湖藻类生长的限制性因素. TN 同时受悬 浮泥沙和水流作用的影响,在上游航道受水流影响较大,在人江水道则主要受陆源污染的影响. TP 含量则主要受悬浮泥 沙和采砂活动的影响, 受水流作用影响相对较小.

关键词: 鄱阳湖; 总氮; 总磷;分布特征; 丰水期

\section{Distribution characteristic of nitrogen and phosphorus in Lake Poyang during high water period}

CHEN Xiaoling ${ }^{1}$, ZHANG Yuan ${ }^{1,3}$, ZHANG Li $^{1,2}$, CHEN Liqiong ${ }^{1}$ \& LU Jianzhong ${ }^{1}$

(1: State Key Laboratory of Information Engineering in Surveying, Mapping and Remote Sensing, Wuhan University, Wuhan 430079, P. R. China)

(2: Key Laboratory of Lake Poyang Wetland and Watershed Research, Ministry of Education, Jiangxi Normal University, Nanchang 330022, P. R. China)

(3: Hubei Province Environmental Monitoring Center, Wuhan 430072 ,P. R. China)

\begin{abstract}
Based on the measured concentration of total nitrogen (TN) and total phosphorus (TP) in Lake Poyang in July 2011, we analyzed the spatial distribution characteristic of TN, TP, and factors affecting them. The nutrient structure and the correlations among nitrogen, phosphorus and chlorophyll-a were discussed. The results show that: The concentration levels of nitrogen and phosphorus have already reached the threshold of eutrophication. TN content has a downward trend from the east part to the west part, and from the south part to the north part, in Lake Poyang. TP contents in several dredging areas were the highest, especially in the border area between south lake and east lake. Phosphorus was limited in Lake Poyang. Comparatively speaking, nitrogen pollution was more serious, and the nitrogen and phosphorus were not the restricting factors of eutrophication. TN content was influenced by suspended sediment concentrations ( SSC) as well as the water flow. It was mostly affected by the water flow in the upstream channels which were largely influenced by the land-sourced pollutants. TP content was less affected by the water flow, but it was mainly influenced by the high SSCs and the dredging activities.
\end{abstract}

Keywords: Lake Poyang; TN; TP; distribution characteristic; high water period

鄱阳湖 $\left(28^{\circ} 11^{\prime} \sim 29^{\circ} 51^{\prime} \mathrm{N}, 115^{\circ} 49^{\prime} \sim 116^{\circ} 46^{\prime} \mathrm{E}\right)$ 是中国最大的淡水湖泊, 位于江西省北部, 长江中下游,

* 国家高技术研究发展计划“863”项目(2012AA12A304)、国家自然科学基金项目 (41101415,41071261)、中央高校 基本科研业务费专项资金项目 (111044)、水利部公益性行业科研专项项目 (201001054)、国家重点实验室仪器设 备专项经费项目和鄱阳湖湿地与流域教育部重点实验室 (江西师范大学) 开放基金项目 (PK2012005) 联合资助. 2012-10-08 收稿;2013-02-25 收修改稿. 陈晓玲,女,1962 年生,教授;E-mail : cxl@ lmars. whu. edu. cn.

** 通信作者; E-mail : chenlq@ whu. edu. cn. 
与赣江、抗河、信江、饶河、修水五条河流尾问相接, 调蓄后经湖口注人长江. 有研究表明, 由于工农业废水及 生活污水的大量排放 ${ }^{[1]}$, 鄱阳湖水环境质量不断下降. 江西省历年水质监测结果表明, 鄱阳湖氮、磷污染越 来越严重, 水体富营养化也进一步加剧 ${ }^{[2]}$. 而氮、磷营养盐是发生水体富营养化的物质条件, 是引起富营养 化的主要因素 ${ }^{[3-6]}$. 因此研究鄱阳湖氮、磷特征,对于鄱阳湖水污染防治有着重要意义.

近年来, 许多学者就鄱阳湖氮、磷含量特征展开了各项调查研究 ${ }^{[7-9]}$ 表明, 鄱阳湖水体氮、磷含量在不断 增加 ${ }^{[10]}$. 胡春华等的研究表明, 鄱阳湖氮、磷含量在空间分布上表现为由人湖口向湖区递减, 湖区向出湖口 增高 ${ }^{[11]}$, 且鄱阳湖氮负荷较大, $N / P$ 比值一直较高, 平均为 $23.28^{[8]}$. 王毛兰等认为, 鄱阳湖主航道 TN、TP 含 量比湖区其它地方高, 且主航道以上游最高 ${ }^{[12]}$. 区铭亮等的研究表明, Chl. a 浓度与 TN、TP 浓度除 9 月份 外,其它时间基本无显著相关性 ${ }^{[13]}$. 本文以 2011 年 7 月份 (丰水期) 鄱阳湖实测数据为基础, 首先分析了丰水 期鄱阳湖水体氮、磷含量的空间分布特征及营养盐结构特征; 其次, 对鄱阳湖主航道 TN、TP 沿水流方向变化趋 势及氮、磷含量与悬浮泥沙浓度的相关性进行了分析, 从而探讨了影响鄱阳湖氮、磷空间分布特征的因素.

\section{1 数据与方法}

\section{1 水样的采集}

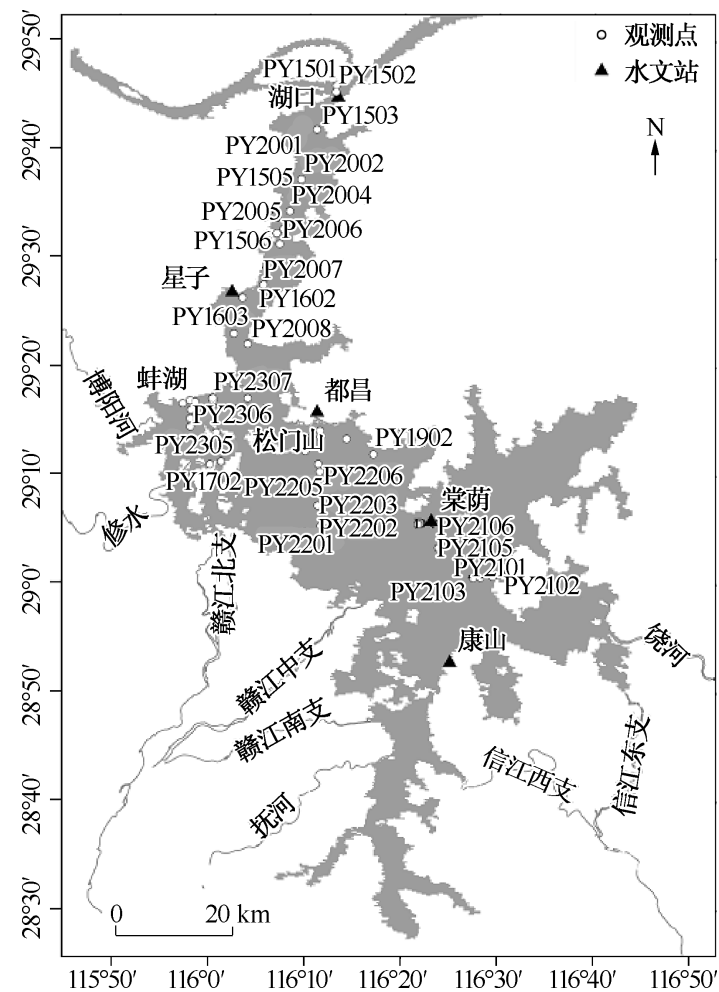

图 12011 年 7 月鄱阳湖水质观测站

Fig. 1 The stations for monitoring water quality of Lake Poyang in July, 2011
2011 年 7 月 $15-23$ 日,在鄱阳湖分别进行 了 9 天共 55 个站位的水质观测与水样采集. 此次 观测时间为丰水期, 9 个航次覆盖了整个鄱阳湖 南北主湖区, 观测站位见图 1 . 每个站点均采集表 层水样,用以进行水体总氮 ( TN) 、总磷 ( TP) 和叶 绿素 a (Chl. a) 等基本水质参数的含量分析.

\section{2 分析方法}

采集的水样经快速定性滤纸过滤后,将滤液 装人聚乙烯瓶中并写好标签, 加硫酸酸化至 $\mathrm{pH}$ 值小于 2 , 置于 $4^{\circ} \mathrm{C}$ 冰箱保存, 带回实验室进行室 内分析.

采用分光光度法进行 TN 、 TP 浓度测定, 所用 仪器为全自动间断化学分析仪 (SmartChem 2000). TN 测定采用碱性过硫酸钾消解紫外分光 光度法 (GB/T 11894-1989) : 先将酸化后的水样 调节为中性, 再加人纯化过的碱性过硫酸钾, 在 $126 \sim 127^{\circ} \mathrm{C}$ 下消者 $30 \mathrm{~min}$, 自然冷却后置于 SmartChem 仪器上用水质总硝酸盐氮的方法进行测 定. TP 测定采用过硫酸钾消解钿酸铵分光光度法 (GB/T 11894-1989) : 先调节水样至中性, 加人过 硫酸钾在 $140^{\circ} \mathrm{C}$ 下消煮 $30 \mathrm{~min}$, 自然冷却后置于 SmartChem 仪器上采用水质正磷酸盐法进行测定.

Chl. a 浓度测定采用苂光法: 先将一定体积的 表层水样经孔径为 $0.45 \mu \mathrm{m}$ 的醋酸纤维滤膜过 滤,再用 $90 \%$ 的丙酮溶液进行色素萃取,最后对提 取的清液重新定容后采用苂光计测定样品溶液和经过 $1 \%$ 的稀盐酸酸化后的样品溶液的苂光值, 获取 Chl. a 浓度. 悬浮泥沙浓度 (SSC) 测定采用美国 Sequoia 公司生产的 LISST-100X.

\section{2 氮、磷空间分布特征}

\section{1 丰水期鄱阳湖水体氮、磷空间分布特征}

对鄱阳湖 2011 年丰水期 55 个实测站点的 TN、TP 含量进行分析后发现: (1) TN、TP 平均含量分别为 
1.389 和 $0.067 \mathrm{mg} / \mathrm{L}$. 目前, 国际上一般认为当水体中 TN 和 TP 的浓度分别达到 0.20 和 $0.02 \mathrm{mg} / \mathrm{L}$ 时, 从营养 盐单因子考虑, 就有可能发生藻类疯长的 “水华” 现象 ${ }^{[14]}$. 从本次观测可见, 当前鄱阳湖已具备并远远超出 了发生富营养化的氮、磷条件. (2) 相较于前人的报告 ${ }^{[6-9]}$, 鄱阳湖丰水期 TN、TP 浓度并没有降低,即鄱阳湖 水质恶化的趋势不仅没有停止,反而有进一步恶化的可能. (3) 根据国家环境保护总局颁布的《地表水环境 质量标准》(GB/T 3838-2002), 鄱阳湖总体属于 IV 类水质,某些区域甚至恶化到 V 类. TP 超过 IV 类地表 水标准 $(0.1 \mathrm{mg} / \mathrm{L})$ 的站点占总站点数的 $12.72 \%, T N$ 超过 $\mathrm{IV}$ 类地表水标准 $(1.5 \mathrm{mg} / \mathrm{L})$ 的站点占总站点数 的 $43.64 \%$. 可见在整个鄱阳湖区, 氮污染相对于磷污染要严重.

以实测站点数据对整个鄱阳湖区进行空间插值,得到丰水期鄱阳湖水体 TN TP 空间分布图 (图 2). 从 空间分布上看, $\mathrm{TN}$ 含量呈现由东向西、由南向北逐渐降低的趋势, 尤其是在饶河和信江东支人湖口一带含 量最高, 与刘倩纯等的研究结果相一致 ${ }^{[15]}$. 这可能是由于鄱阳湖北部平均流速大于湖体中部区, 且大于南部 区, 高流速有利于湖水中氮的稀释 ${ }^{[16]}$. TP 含量并没有像 TN 一样呈现明显的空间递减变化趋势, 而是在湖泊 中心区域出现极高值或极低值, 与胡春华等提取的悬浮物含量分布图相一致 ${ }^{[17]}$. 将 TP 分布与刘子波在 2011 年丰水期提取的鄱阳湖几个主要的采砂区相对比, 可以发现 TP 极高值所在区域均为主要采砂区 ${ }^{[18]}$.
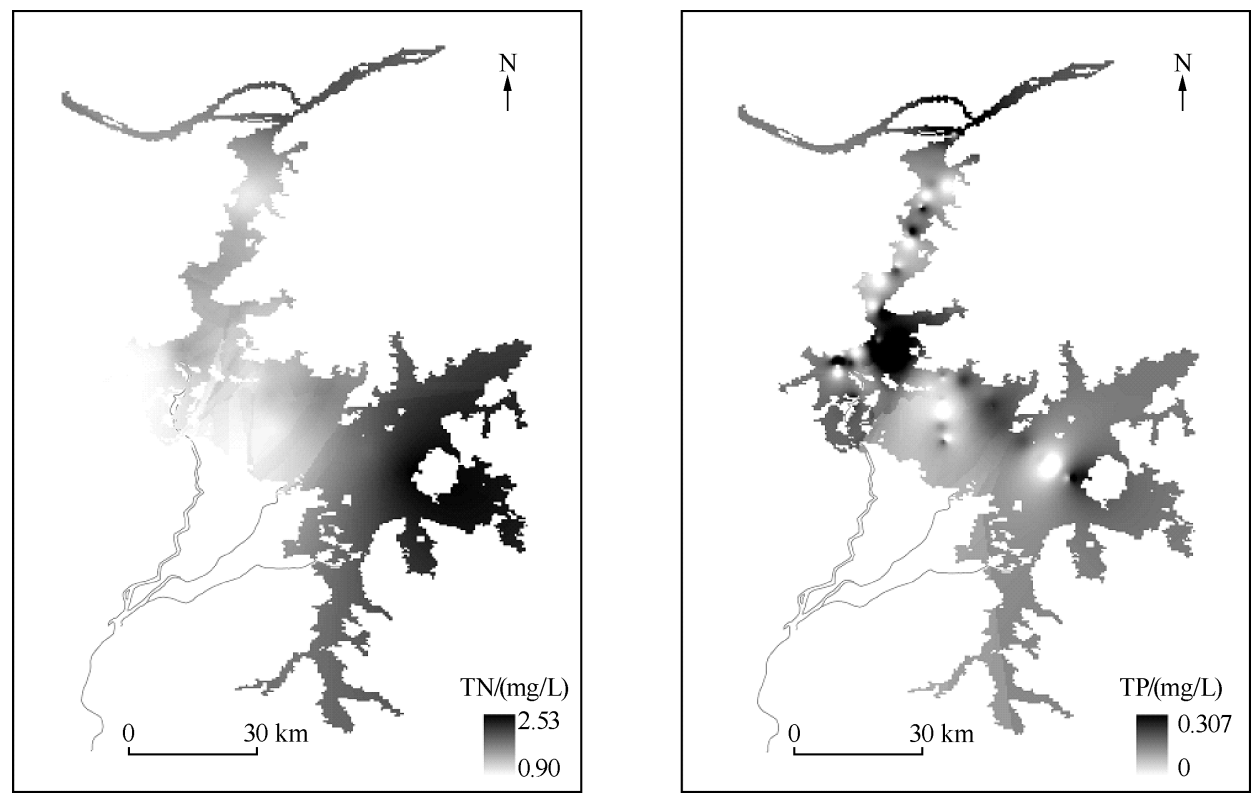

图 2 鄱阳湖 2011 年 7 月 TN、TP 空间分布

Fig. 2 Spatial distribution of TN and TP of Lake Poyang in July, 2011

\section{2 鄱阳湖氮、磷营养盐结构特征及其与 Chl. $\mathrm{a}$ 的相关性}

氮、磷比 $(\mathrm{N} / \mathrm{P})$ 被广泛地作为考察营养盐结构的主要指标 ${ }^{[19]}$. 根据 Redfield 的研究 ${ }^{[20]}$, 若 N/P 值小于 16 , 说明污染物中氮为限制因子, 磷相对充足; 若大于 16 , 说明磷为限制因子, 氮相对充足 ${ }^{[11,21]}$. 对鄱阳湖 2011 年丰水期各站点水样数据进行营养盐结构分析, 其中 41 个站点表现为磷限制, 占总站点数的 $74.5 \%$, 平均 $\mathrm{N} / \mathrm{P}$ 为 21.33 . 说明鄱阳湖区以磷限制为主, 氮污染相对比较严重, 与 2.1 中分析结果相吻合, 也与胡春 华的研究结果一致 ${ }^{[8]}$.

氮、磷营养盐的含量变化可以影响浮游植物的丰度,而浮游植物的生长状况又是营养盐含量变动的主 要条件 ${ }^{[22]}$. Chl. a 是浮游植物体内的主要成分, 研究其与营养盐的关系对于研究湖泊富营养化具有重要意 $义^{[23-24]} . \mathrm{TN} 、 \mathrm{TP}$ 浓度与 Chl. a 均无显著相关性, 相关系数分别为 $0.0055(n=55)$ 和 $0.0008(n=50)$, 说明在 鄱阳湖,氮、磷不是藻类生长的限制性因素. 影响藻类生长的因素包括营养盐含量、光照、水温、酸碱度及水 体自身的水文条件等 ${ }^{[25]}$. 有研究表明,过于浑浊的水体对所有藻类的生长都有抑制作用 ${ }^{[26]}$,而受到 “五河” 
来水含沙量和湖区采砂等人为因素的影响, 鄱阳湖近几年悬浮泥沙含量增加, 水体浑浊度加剧 ${ }^{[27]}$, 加之鄱阳 湖水体具有较大的流动性, 这可能是抑制藻类生长的主要原因. 因此, 尽管目前鄱阳湖氮、磷营养盐含量已 远超过富营养水平,藻类的含量却没有达到暴发大面积水华的程度.

\section{3 鄱阳湖氮、磷空间分布特征影响因子分析}

\section{1 水流对 TN、TP 含量的影响}

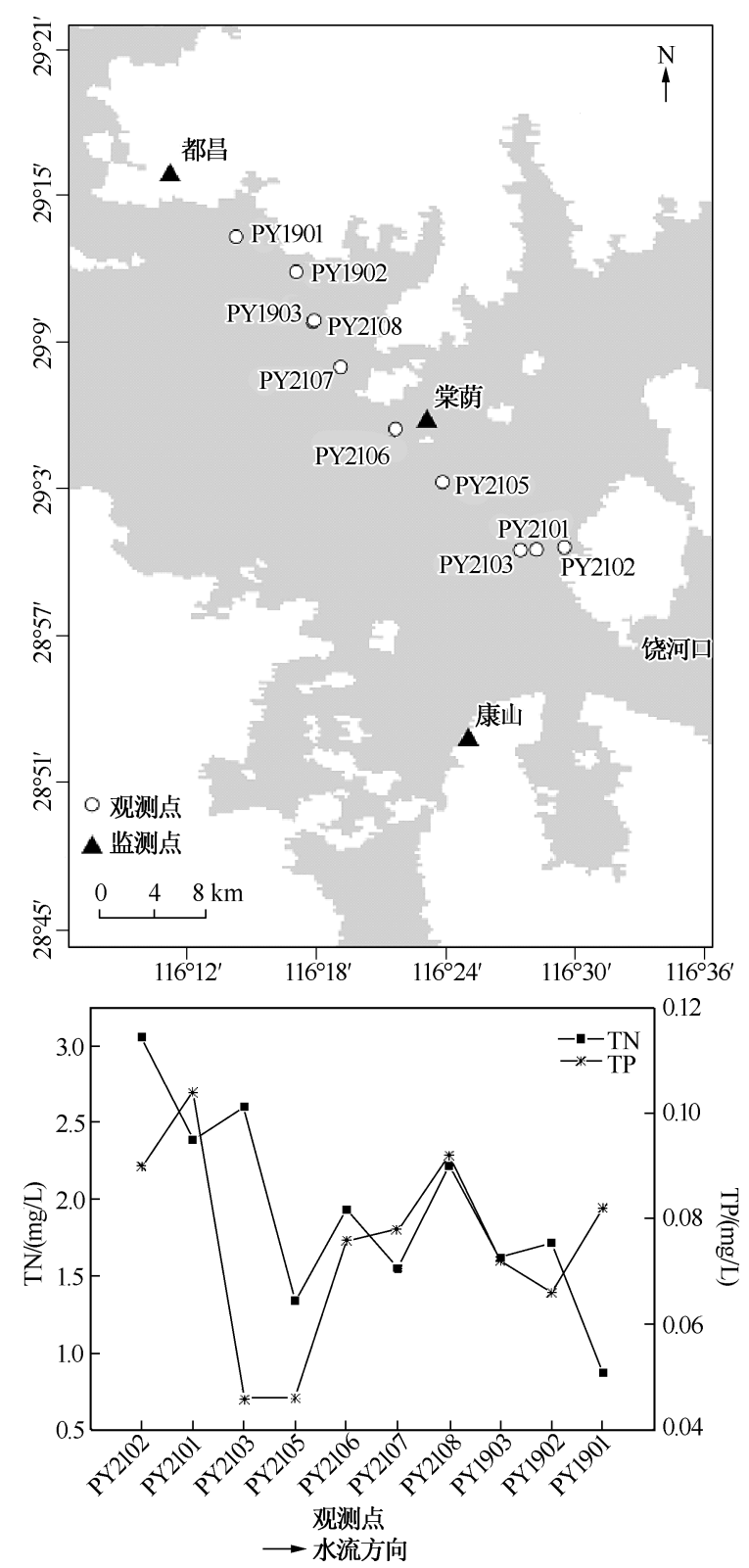

图 3 鄱阳湖饶河口至都昌段 $\mathrm{TN}$ 、 TP 含量变化趋势

Fig. 3 Change trend of TN and TP from Raohe section to Duchang section in Lake Poyang
为进一步分析 $\mathrm{TN} 、 \mathrm{TP}$ 含量受水流的影 响, 选取鄱阳湖主航道饶河口至都昌段和星子 至湖口段沿水流方向的站点进行分析.

3.1 .1 饶河口至都昌段 TN $\mathrm{TP}$ 沿水流方向变 化趋势 沿饶河口至都昌段共采集了 10 个站 点, 结果表明, TN 总体上呈锯齿状下降的趋 势; TP 波动比较大, 最高值在上游 PY2102 和 PY2101 2 个站点, 接着陡降至最低值, 然后变 化较缓 (图 3). 分析其原因为: PY2101 和 PY2102 在饶河人湖口, 饶河是主要的粮食和 渔业区, 化肥、农药和水产养殖所投放的饲料 等都会对水质造成严重污染 ${ }^{[28]}$, 因此这 2 个 站点 TN、TP 含量都比较高. 根据刘子㴋的研 究 ${ }^{[18]}$, 饶河口至都昌段是鄱阳湖典型的采砂 区, 尤其在 PY2106 至 PY2107 间采砂情况比 较严重, 受采砂的影响 TP 浓度又逐渐升高, $\mathrm{TN}$ 浓度也表现出一定程度的波动. 而都昌段 城市污水径流可能使 PY2108 站点的氮、磷浓 度又高于邻近其它站点. 因此, 综合分析, 在鄱 阳湖主航道上游, TN 含量受水流影响较大, 沿 水流方向呈下降趋势; TP 含量则受悬浮泥沙 影响较大, 总体上无明显变化规律.

3.1 .2 星子至湖口段 TN、TP含量沿水流方向 变化趋势 考虑到采样时间和天气环境等外 界因素的影响, 对星子至湖口段取同一天采集 的 6 个站点进行数据分析发现, TN 含量呈明 显上升趋势, TP 含量变化比较平缓, 但在出湖 口陡增. 从 TN 含量的分析来看, 由星子至湖口 段为鄱阳湖人江水道最北面的一段, $\mathrm{TN}$ 含量 从 PY1505 站点开始呈现明显的递增趋势 (图 4 ). 星子至湖口采砂中间 (主要是星子县海会 镇) 有一较大工业园地带, 且湖口地区又是个 主要的棉花产区, 面源污染的影响可能是此段 TN 含量不断上升的主要原因. 因此, 此段 TN 含量的增加除了受南部湖区来水的影响外, 还 受陆源输人影响. 而由鄱阳湖外业观测记录可 知, 6 个站点均在同一环境下测量, 但站点 PY1506 底质为泥, PY1505 底质为草, 其余 4 个 
站点底质为沙, 且 PY1506 站点靠近岸边, 都可 能是导致该点 TN 含量趋势不一致的原因. 从 TP 含量分析来看, 在湖口处, TP 含量瞬间增 高, 表明长江水体的 TP 含量要远高于鄱阳湖输 人的 TP 含量. 从同步观测的总悬浮泥沙含量也 可以看出, 长江中心 PY1501 的悬浮泥沙含量 为 $65 \mathrm{mg} / \mathrm{L}$, 是鄱阳湖出湖口 PY1502 与长江交 界处 $(32 \mathrm{mg} / \mathrm{L})$ 的 2 倍, 悬浮泥沙含量急剧增 高. 而 TP 多数是由泥沙携带运移, 所以在星子 至湖口段变化比较平稳. 因此,在鄱阳湖人江水 道, TN 含量可能由于受陆源污染的影响, 呈明 显上升的趋势; TP 含量则主要受悬浮泥沙影 响, 呈先稳定后上升的趋势.

综合分析表明,在鄱阳湖上游主航道 TN 含量受水流作用明显,在饶河口至都昌段呈下 降趋势. 在人江水道,则主要受陆源污染的影 响, 由星子至湖口段呈明显递增的趋势. 而 TP 含量在整个主航道, 受水流作用影响不显著, 受悬浮泥沙影响较大, 总体上无明显变化 规律.

\section{2 泥沙对 TN、TP 含量的影响}

大量研究表明,泥沙对营养性污染物氮、磷 都具有吸附作用,与水流共同成为污染物质的 主要载体,改变污染物质在水体中的存在形态 和迁移过程 ${ }^{[29]}$. 将 TN 、TP 含量分别与悬浮泥沙 浓度 (SSC) 做相关性分析, 均达到了显著正相 关 (图 5), TN 与 SSC 双侧 Pearson 相关系数为 $0.467(P=0.006), \mathrm{TP}$ 与 SSC 双侧 Pearson 相 关系数为 $0.440(P=0.010)$, 说明鄱阳湖 $\mathrm{N} 、 \mathrm{P}$ 含量在很大程度上是受悬浮泥沙影响. 而鄱阳 湖采砂情况严重, 采砂引起底质的再悬浮, 因此 鄱阳湖严重的采砂活动也是影响氮、磷含量的 重要因素。

\section{4 参考文献}
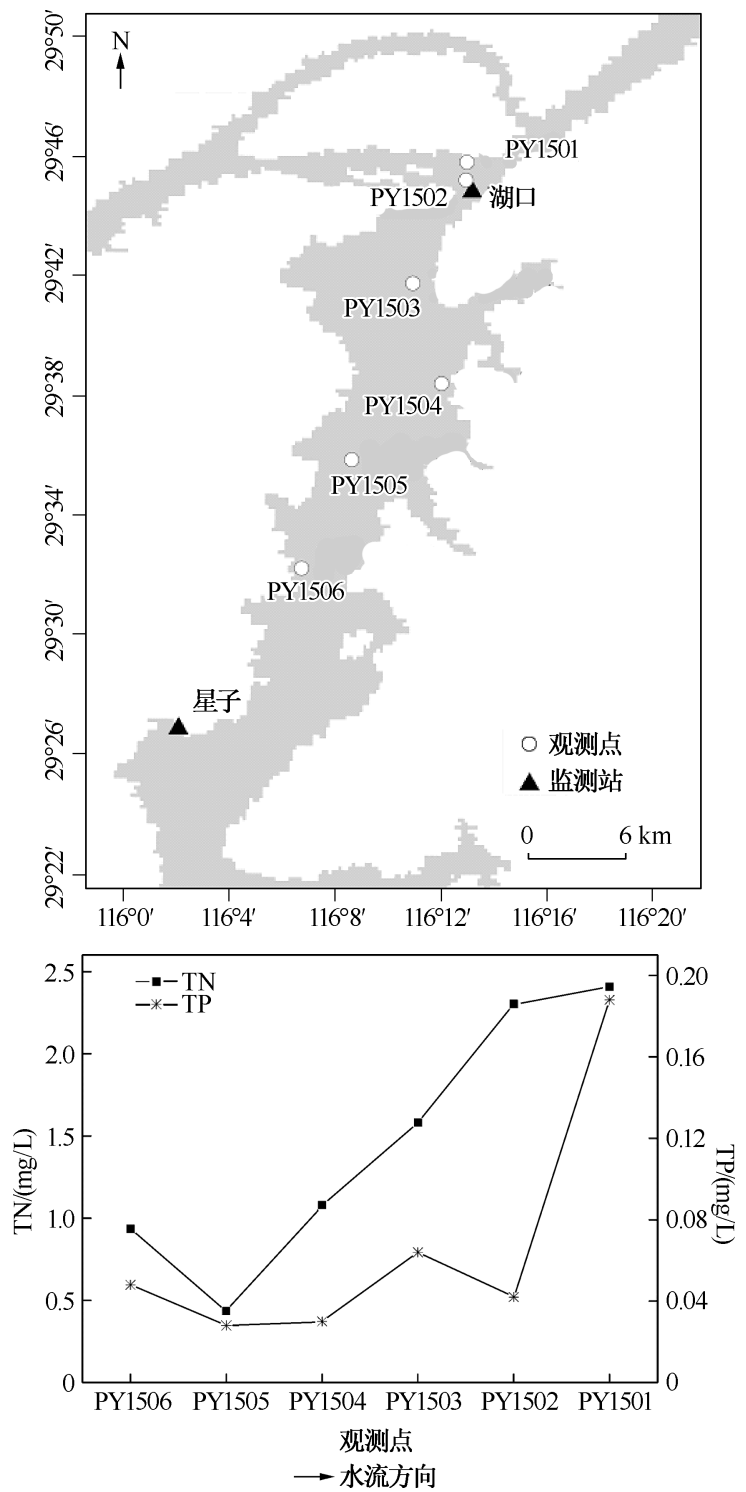

图 4 鄱阳湖星子至湖口段 $\mathrm{TN}$ 、 $\mathrm{TP}$ 变化趋势

Fig. 4 Change trend of TN and TP from Xingzi section to Hukou section in Lake Poyang

[ 1 ] 夏黎莉,周文斌. 鄱阳湖水体氮、磷污染特征及控制对策. 江西化工,2007,(1):105-107.

[ 2 ] 余进祥,刘娅菲,钟晓兰等. 鄱阳湖水体富营养化评价方法及主导因子研究. 江西农业学报,2009,21 (4) : 125-128.

[ 3 ] Correll DL. The role of phosphorus in the eutrophication receiving waters : a review. J Environ Qual, 1998, 27: 261-266.

[ 4 ] Daniel TC, Sharpley AN, Lemunyon JL. Agricultural phosphorus and eutrophication. a symposium overview. J Environ Qual. 1998, $27: 251-257$.

[ 5 ] Camargo JA, Alonso A. Ecological and toxicological effects of inorganic nitrogen in aquatic ecosystems: A global assessment. Environment International, 2006, 32(6) : 831-849.

[6] 王毛兰, 胡春华,周文斌. 丰水期鄱阳湖氮、磷含量变化及来源分析. 长江流域资源与环境,2008,17(1):138-142.

[7] 夏黎莉,周文斌. 鄱阳湖水体氮、磷污染特征及控制对策. 江西化工,2007,(1):105-107.

[8] 胡春华. 鄱阳湖水环境特征及演化趋势研究 [学位论文].南昌:南昌大学,2010. 

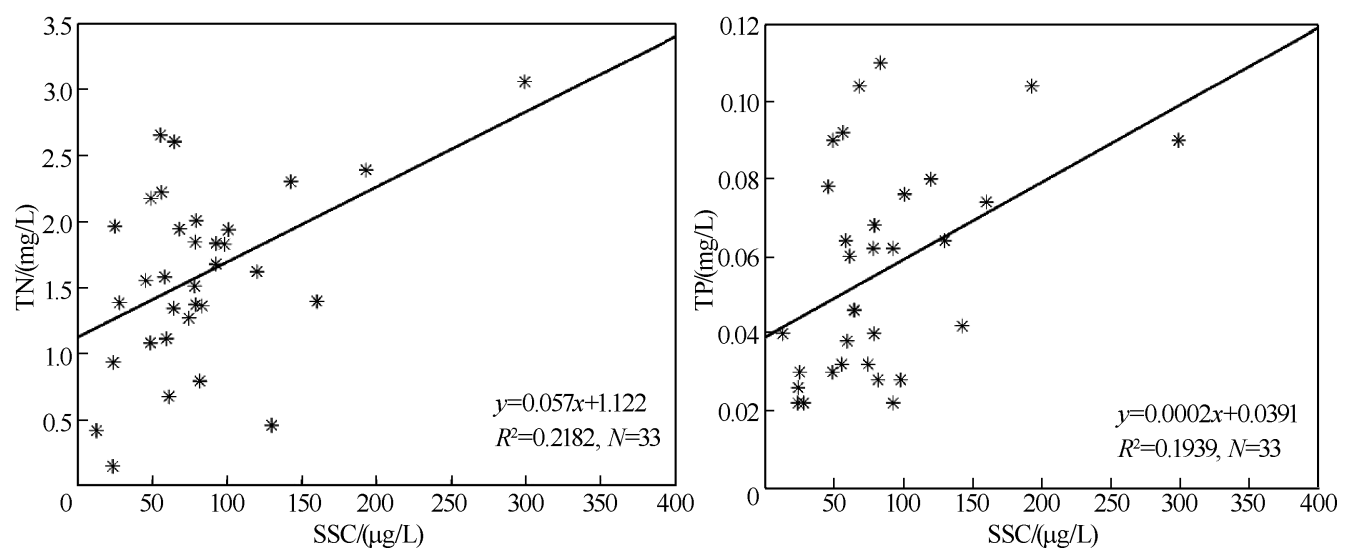

图 5 氮、磷与县浮泥沙浓度相关性分析

Fig. 5 The correlation between nitrogen, phosphorus and suspended sediment concentrations

[9] 王毛兰,周文斌,胡春华. 鄱阳湖区水体氮、磷污染状况分析. 湖泊科学, 2008,20(3):334-338.

[10] 胡春华, 施 伟, 胡龙飞等. 鄱阳湖水利枢纽工程对湖区氮、磷营养盐影响的模拟研究. 长江流域资源与环境, $2012,21(6): 749-755$.

[11] 胡春华, 周文斌, 王毛兰等. 鄱阳湖氮、磷营养盐变化特征及潜在性富营养化评价. 湖泊科学, 2010,22 (5): 723-728.

[12］王毛兰. 鄱阳湖流域氮、磷时空分布及其地球化学模拟 [学位论文].南昌:南昌大学,2007.

[13］区铭亮,周文斌,胡春华. 鄱阳湖叶绿素 a 空间分布及与氮、磷质量浓度关系. 西北农业学报,2012,12(6): 162-166.

[14] 黄玉瑶. 内陆水体污染生态学研究. 北京:科学出版社,2001:37.

[15] 刘倩纯, 胡 维, 葛 刚等. 鄱阳湖枯水期水体营养浓度及重金属含量分布研究. 长江流域资源与环境,2012,21 (10):1230-1235.

[16] 顾 平,万金保. 鄱阳湖水文特征及其对水质的影响研究. 环境污染与防治, 2011,33(3):15-20.

[17］胡春华,周文斌,卢 林. 基于 GIS 平台的鄱阳湖采砂区域规划研究. 人民长江,2011,42(4):8-11.

[18］刘子潇.鄱阳湖采砂活动遥感监测研究 [ 学位论文].武汉:武汉大学, 2012.

[19］彭云辉,孙丽华,陈浩如等. 大亚湾海区营养盐的变化及富营养化研究. 海洋通报,2002,21(3):44-48.

[20] Redfield AC. The biological control of chemical factors in the environment. Am Sci, 1958, 46(3) : 205-221.

[21] 曲丽梅,姚 德, 丛巫福. 辽东湾氮、磷营养盐变化特征及潜在性富营养评价. 环境科学, 2006,27(2):263-267.

[22] 吴阿娜, 朱梦杰, 汤 琳等. 淀山湖蓝藻水华高发期叶绿素 a 动态及相关环境因子分析. 湖泊科学, 2011,23(1): $67-72$.

[23] 杨清心. 太湖水华成因及控制途径初探. 湖泊科学,1996,8(1):67-74.

[24] 杨志岩, 李畅游, 张 生等. 内蒙古乌梁素海叶绿素 a 浓度时空分布及其与氮、磷浓度关系. 湖泊科学, 2009,21 (3) : 429-433.

[25] 王利利. 水动力条件下藻类生长相关影响因素研究 [学位论文]. 重庆:重庆大学,2006.

[26] Froeyshov O. The bacitracins: properties, biosynthesis and fermentation. In: Vandamme EF ed. Biotechnology of industrial antibiotics. Marcel Dekker, Inc Basel, 1984 :655-694.

[27] 江 辉. 鄱阳湖透明度遥感反演及其时空变化研究. 中国农村水利水电, 2012,(1):30-33.

[28] 胡绵好, 袁菊红, 卢福财等. 鄱阳湖典型区段水体氮、磷等污染发生频率与成因特征研究. 水资源与水工程学报, $2012,23(1): 14-17$.

[29］李 灿. 三峡库区重庆段泥沙对富营养化影响研究 [学位论文]. 重庆:重庆大学,2005. 